José Manuel Jiménez Rodríguez

Profesional del Servicio Andaluz de Salud. Profesor asociado en la Facultad de Trabajo Social de la Universidad de Granada. Granada. España. Profesor colaborador en el área de Ciencias de la Salud de la Universitat Oberta de Catalunya.

Correo electrónico: jose.jimenez.rodriguez.sspa@juntadeandalucia.es

Recibido el 26 de agosto de 2019; aceptado el 2 de septiembre de 2019.

\section{Derecho sociosanitario, voluntad vital anticipada y muerte digna en España: un análisis a la situación jurídico-sanitaria actual desde el Trabajo Social}

\section{Socio-health law, living will and dignified death in Spain: an analysis of the current legal-health situation from the Social Work}

\section{Sr. Director:}

En España, la sanidad se gesta bajo un modelo mixto y un sistema conservador donde el paternalismo médico constrińe el derecho a la autodeterminación clínica. Y condiciona la relación médico-paciente. Esa relación, de carácter unidireccional, altera la voluntad del paciente quien, en una posición de subordinación, acepta las medidas y actuaciones terapéuticas por orden de aquel ${ }^{1}$. En ocasiones, "hostigantes" y en perjuicio del interés particular de este y de su legitimidad como individuo. El neoliberalismo, entendido como una corriente propia de sistemas derechistas, aleja al ciudadano de los derechos sociales; hecho que afecta a los derechos decisorios ${ }^{2}$. La configuración en España de un Estado social democrático y de derecho reduce los márgenes del conservacionismo político y abre paso a un modelo progresista con efectos positivos sobre el bienestar social ${ }^{3,4}$. Es aquí donde se enmarcan, entre otros, los derechos sanitarios de primera y segunda generación. Y en concreto, el derecho a la declaración de voluntad vital anticipada (VVA). Esta figura surge en España como consecuencia de la Ley 41/2002, de 14 de noviembre, básica reguladora de la autonomía del paciente y derechos y obligaciones en materia de información y documentación clínica (art. 11, sobre las instrucciones previas). Previamente, el Convenio del Consejo de Europa para la protección de los derechos humanos y la dignidad del ser humano respecto de las aplicaciones de la biología y la medicina (suscrito en Oviedo el 4 de abril de 1997, ratificado en el año 1999 y entrado en vigor en el año 2000) hace referencia en su articulado al derecho a la información y al consentimiento libre. Tales preceptos normativos otorgan legitimidad y autonomía al paciente como individuo. Y limitan las medidas terapéuticas de carácter asistencial, pues desde su puesta en marcha, el consentimiento del paciente es considerado. Tal consideración sitúa a dicho paciente en un primer plano y lo dota de competencia y opciones sanitariamente manifiestas en la citada ley ${ }^{5}$. Esto posibilita nuevos escenarios clínico-asistenciales y otros espacios de comunicación y diálogo, donde el asistencialismo sanitario se ve coartado. La ley de VVA y el derecho a la muerte digna es multifactorial y puede estar influida por el contexto sociopolítico, las corrientes y movimientos ideológicos del momento, la jurisdicción, el sistema de valores y creencias del otorgante, sus preferencias sanitarias, etc. Uno de los mayores problemas y retos que plantea esta norma son la falta de unidad conceptual y la inexistencia de una normativa específica a nivel nacional que regule este precepto legal. Son las distintas comunidades autónomas, adheridas al país, pioneras en la promulgación de normas explícitas reguladoras de la VVA. Actualmente, a excepción de Asturias y de las ciudades de Ceuta y Melilla, todas las comunidades autónomas cuentan con una norma específica reguladora de la VVA. Bien sea a través de una ley, un decreto ley, un decreto o una orden.

En lo concerniente a la ley que garantiza el derecho a la muerte digna, la situación varía. Esta, al igual que la otra, irrumpe en el aparato normativo español de manera irregular y por ende en las comunidades autónomas. Pero actualmente solo el 52,8\% del conjunto de comunidades autónomas de Espańa cuenta con una normativa propia, dato que representa a poco más de la mitad del país. Es la Comunidad Autónoma de Andalucía pionera de esta materia ${ }^{6}$. El año 2015 representa el mayor índice de leyes aprobadas con un 30\% (tabla 1).

El déficit en la conformidad de normativas nacionales relativas a la VVA y el derecho a la muerte digna suponen un obstáculo para los derechos del paciente, y desencadena agravios comparativos. Tal ausencia genera impedimentos para el desarrollo normativo sanitario y puede limitar las actuaciones del paciente en el proceso de la planificación anticipada de las decisiones 
Tabla 1. Marco normativo sobre muerte digna en España

\begin{tabular}{|c|c|c|}
\hline Rango & Comunidad autónoma & Denominación \\
\hline Ley & Andalucía & Ley 2/2010, de 8 de abril, de derechos y garantías de la dignidad de la persona en el proceso de la muerte \\
\hline Ley & Aragón & Ley 10/2011, de 24 de marzo, de derechos y garantías de la dignidad de la persona en el proceso de morir y de la muerte \\
\hline Ley & Navarra & Ley Foral 8/2011, de 24 de marzo, de derechos y garantías de la dignidad de la persona en el proceso de la muerte \\
\hline Ley & Canarias & Ley $1 / 2015$, de 9 de febrero, de derechos y garantías de la dignidad de la persona ante el proceso final de su vida \\
\hline Ley & Baleares & Ley 4/2015, de 23 de marzo, de derechos y garantías de la persona en el proceso de morir \\
\hline Ley & Galicia & Ley $5 / 2015$, de 26 de junio, de derechos y garantías de la dignidad de las personas enfermas terminales \\
\hline Ley & País Vasco & Ley 11/2016, de 8 de julio, de garantía de los derechos y de la dignidad de las personas en el proceso final de su vida \\
\hline Ley & Madrid & Ley 4/2017, de 9 de marzo, de derechos y garantías de las personas en el proceso de morir \\
\hline Ley & Asturias & Ley 5/2018, de 22 de junio, sobre derechos y garantías de la dignidad de las personas en el proceso del final de la vida \\
\hline Ley & Comunidad Valenciana & Ley 16/2018, de 28 de junio, de derechos y garantías de la dignidad de la persona en el proceso de atención al final de \\
\hline
\end{tabular}

\section{- BIBLIOGRAFÍA}

1. Cañete R, Guilhem D, Brito K. Paternalismo médico. Rev Med Electro. 2013;35(2):144-52.

2. López 0 , Jarillo EC. La reforma neoliberal de un sistema de salud: evidencias del caso mexicano. Cad Saúde Pública. 2017;33(2):1-13.

3. Feo 0 . Las políticas neoliberales y su impacto sobre la formación en salud pública. Comentarios sobre la experiencia venezolana. Med Social. 2008:3(4):275-84
4. Matias SR. Neoliberalismo, neoconstitucionalismo y democracia Diálogo de Saberes. 2013;39:69-86.

5. Jiménez JM. Voluntad vital anticipada: un derecho reconocido en territorio español y Andalucía. En: Ortiz L, ed. Espacios para hablar y compartir sobre la intervención social y educativa en grupos vulnerables. Almería: Enfoques Educativos S.L.; 2015. p. $691-98$
6. Jiménez JM. Planificación anticipada de las decisiones en atención primaria: un análisis comparativo desde el trabajo social. Trabajo Soc y Salud. 2018:89:7-15. 